\title{
Enhanced reliability of yttria-stabilized zirconia for dental applications
}

\author{
Erik Camposilvan ${ }^{1,2}$, Fernando Garcia Marro $^{1,2}$, Alvaro Mestra $^{1,2}$ and Marc Anglada $^{1,2, *}$ \\ ${ }^{1}$ Department of Materials Science and Metallurgical Engineering, \\ Universitat Politècnica de Catalunya, Av. Diagonal 647, 08028 Barcelona - Spain \\ 2 Center for Research in NanoEngineering CRnE, Universitat Politècnica de Catalunya, Av. \\ Diagonal 647, Barcelona, 08028, Spain \\ * Corresponding author \\ E-mail: marc.j.anglada@upc.edu \\ Phone number: +34934016701 \\ Fax number: + 34934016706
}

\begin{abstract}
An increasing number of dental applications based on yttria-stabilized zirconia (3Y-TZP) have been developed in recent years as a result of the advances and versatility of dry-processing and soft machining at the pre-sintered state. Nonetheless, the long-term surface stability of these materials in humid environment is still a matter of concern and may limit its application. In this work, a simple method to prevent hydrothermal degradation on zirconia surface is studied in detail. This method involves the infiltration of pre-sintered parts with optimized solutions containing Ce salts, leaving unchanged the other processing steps, allowing the diffusion of Ce during conventional sintering. Several pre-sintering conditions, solution concentrations and sintering temperatures were studied and characterized, obtaining working parameters for the production of zirconia parts with mechanical properties similar to standard 3Y-TZP and high resistance to hydrothermal aging. This optimal combination was obtained with the $1150{ }^{\circ} \mathrm{C}$ pre-sintering temperature, $50 \mathrm{wt} \%$ solution and sintering at $1450{ }^{\circ} \mathrm{C}$, leading to a superficial $\mathrm{CeO}_{2}$ content of about $3 \mathrm{~mol} \%$.
\end{abstract}

Keywords: Infiltration, Zirconia, Low Temperature Degradation, Dental implant, Ceria, 3Y-TZP. 


\section{Introduction}

Tetragonal polycrystalline zirconia stabilized with $3 \mathrm{~mol} \%$ of yttria (3Y-TZP) is a biocompatible ceramic with good mechanical properties and a white translucent color, which makes it suitable as a structural material in biomedical implants and dentistry. Transformation toughening is the mechanism behind the mechanical behavior of $3 \mathrm{Y}$-TZP. The tetragonal phase, stable above $1000{ }^{\circ} \mathrm{C}$ in pure zirconia, is retained to room temperature in a metastable state by adding a suitable amount of yttria, which acts as stabilizer. This metastable phase is able to undergo stress-induced transformation thanks to the high stresses arising in front of a crack under external loading. The product is the stable monoclinic phase, which has a specific volume approximately $4.5 \%$ higher than the tetragonal phase. This local transformation has a displacive character and the increase in volume generates compressive stresses around the growing crack, hindering its propagation and thus increasing the fracture toughness of the material. The transformability of the tetragonal phase is the key parameter in Y-TZP: the stabilizer content should be high enough to avoid transformation during cooling from the sintering temperature, but low enough to guarantee metastability in the tetragonal phase so that $t-m$ transformation can be activated by stress. With $3 \mathrm{~mol} \%$ of yttria, a fair combination of bending strength (higher than $1000 \mathrm{MPa}$ ) and fracture toughness (about $5 \mathrm{MPa} \sqrt{\mathrm{m}}$ ) can be achieved [1].

\subsection{Zirconia in arthroplasty and dentistry}

Zirconia started to be employed in total hip arthroplasty in the late 80's, when it became an alternative to alumina for manufacturing femoral heads, since its higher strength and fracture toughness could offer more flexibility in terms of design and the possibility to implant less invasive prosthesis. In the last years, 3Y-TZP has also been used for the production of various dental devices (crowns, bridges, abutments, fixed partial dentures-FPDs and dental implants), where translucency 
and easy color modification for matching teeth shade represent big advantages for 3Y-TZP with respect to metal and metal-ceramic parts $[2,3]$.

The production of $3 \mathrm{Y}$-TZP femoral heads dropped drastically after finding that slight alterations in the processing steps could lead to failure of ceramic balls partly due to lowtemperature degradation (LTD) [4]. This phenomenon, often referred to as hydrothermal degradation or aging, occurs in humid environments and at moderate temperatures (including human body temperature). LTD consists of the spontaneous and progressive formation of monoclinic phase under hydrothermal exposure, inducing surface roughening, localized stress, microcracking and often grain pull-out. The effects of LTD become evident when degraded parts are subjected to wear since large quantities of debris are produced and the wear rate dramatically increases with respect to non-degraded zirconia [5]. Even though in near fully-dense 3Y-TZP parts LTD may only interest a superficial layer of few micrometers, in poorly sintered pieces with significant residual porosity, the bulk may be affected leading eventually to failure [6]. For these reasons, new composites of alumina/zirconia (zirconia-toughened alumina, ZTA) have been developed, which offer similar or improved mechanical properties and are barely affected by LTD.

However, 3Y-TZP is now attracting increasing interest in dentistry, thanks to the latest improvements in CAD/CAM processing and the possibility to color the visible parts by doping or by veneering to match the natural teeth shade $[7,8]$. It is also becoming clear that zirconia can be osseoconductive, so dental implants with tailored superficial porosity and roughness are being developed [9]. In these applications, a solid anchor of the implant to the bone is needed during the whole life of the patient. Due to the relatively high cyclic contact loading during mastication, crack nucleation and propagation by subcritical crack growth should be avoided, therefore the effect of the environment must be considered. In the current generation of 3Y-TZP, a small content of $\mathrm{Al}$ (less than $0.5 \%$ ) is added in order to reduce the LTD kinetics [10], but the material still suffers from this phenomenon. Even though the effects of LTD on the flexural strength of dental zirconia under 
monotonic and cyclic loading seems to be limited and dependent on the aging time $[11,12]$, this issue is still a matter of concern [13-15] and represents an impediment to the development of allceramic dental systems. Better solutions are therefore needed to overcome the problem, which is the subject of this work.

\subsection{Ce doping in zirconia}

The presence of vacancies in the $\mathrm{ZrO}_{2}$ lattice generated by $\mathrm{Y}_{2} \mathrm{O}_{3}$ addition has been recognized as the key point for stabilization of the tetragonal phase at room temperature. During hydrothermal aging these vacancies may operate as hosting sites for the diffusion of water species from the surrounding environment, reducing their number and destabilizing the tetragonal crystal structure [16]. Other stabilizers can be employed instead of Yttrium. In the case of Cerium, due to the tetravalent character of $\mathrm{Ce}^{4+}$ ion that forms solid solution with zirconia, the vacancy mechanism is not operative, and therefore the stabilization of the tetragonal phase given by $\mathrm{Ce}^{4+}$ is imputable to the oversized dimension of this ion. $\mathrm{Ce}^{+4}$ forms a random substitutional solution into the $\mathrm{Zr}$ tetragonal lattice, but adopting a more symmetric 8 -fold coordination due to the bigger size of $\mathrm{Ce}^{4+}$ with respect to $\mathrm{Zr}^{4+}$, resulting in decreased tetragonality of the unit cell, and the stabilization of the tetragonal and cubic phases [17].

Ce-stabilized zirconia (Ce-TZP) is far more resistant to hydrothermal ageing than 3Y-TZP [18]. However, both $10 \mathrm{Ce}-\mathrm{TZP}$ and $3 \mathrm{Y}-\mathrm{TZP}$ have almost the same $\mathrm{t}-\mathrm{m}$ transformation temperature $T_{0}$, implying a similar driving force for transformation. Therefore, materials with the same driving force (as can be estimated in terms of $T_{0}$ ) can exhibit very different LTD kinetics $[18,19]$. The slower kinetics in Ce-TZP may be reasonably related to the lack of extrinsic vacancies when Ce is still in the initial oxidized state 4+. The first steps of degradation may thus be blocked and this could explain why aging is strongly retarded. Nevertheless, hydrothermal aging is still present in Ce-TZP, with a very sluggish kinetics, so the explanation offered is not sufficient. Probably, the 
vacancies naturally present in zirconia lattice at room temperature or retained after sintering are responsible for inducing aging. The presence of a limited amount of $\mathrm{Ce}^{3+}$ ions is also not to be excluded [20]. Other authors state that ceria apparently segregates into grain boundary or produces a thin film of $\mathrm{CeO}_{2}$ on the surface of the sample, preserving Y-TZP "active points" that would be responsible for initiating the aging phenomenon [21].

Cerium can be added to Y-TZP improving significantly the aging resistance. Nonetheless, it has been observed that the co-doping increases the grain size and somehow reduces the sintering capabilities of the material leaving some residual porosity [22]. Indeed, the development of new materials stabilized with both $\mathrm{Ce}$ and $\mathrm{Y}$ will be confronted to the challenge of finding the right balance between $\mathrm{Ce}$ and $\mathrm{Y}$ in order to optimize both mechanical and aging behaviors. Increasing Ce and Y content may produce high hydrothermal ageing resistance but low fracture toughness because of lower transformability [18] as it occurs with the sole Y doping when its content is increased over $3 \mathrm{~mol} \%$. On the other side, doping with only high Ce concentration makes the material immune to LTD but also induces low hardness and strength.

Another possible strategy is to increase the Ce content only in the superficial region. Diffusion of ceria in the surface of zirconia was performed by heat-treating Y-TZP into ceria powder beds [23]. In a similar fashion, Marro et al. [24] have either pressed a layer of $\mathrm{CeO}_{2}$ powder on the surface of dense 3Y-TZP or deposited a thin film of ceria on the surface, followed by annealing to allow diffusion into 3Y-TZP. As a result, hydrothermal aging was prevented on the Ce-rich face in both cases, without impairing surface mechanical properties with respect to the standard 3Y-TZP.

The objective of the present paper is precisely to study a method for adding ceria to $3 \mathrm{Y}$-TZP, with higher concentrations in the surface, in order to improve its long-term surface stability. The method should easily adapt to dry processing of zirconia ceramic parts, commonly used to manufacture dental prosthesis. This method starts from spray-dried granules of sub-micrometric powders with tailored characteristics, which are usually pressed isostatically in a deformable mold. 
The green piece is then pre-sintered in air, obtaining a porous machinable preform which can be soft machined via CAD/CAM before sintering in air between 1350 and $1600{ }^{\circ} \mathrm{C}$ [25]. Infiltration processing was chosen for this purpose since it can be easily adapted to dry-processing. By this method, the pre-sintered blank is infiltrated with a Ce solution after soft machining, leaving unchanged the other usual processing steps.

\subsection{Infiltration processing}

Infiltration processing has been employed to add alumina to zirconia by soaking pre-sintered cylinders into molten Al nitrate salts [26]. Infiltration with Ce acetate was adopted for coloring purposes, observing no change in mechanical properties up to concentration of $5 \mathrm{wt} \%$ in water solutions [7]. Ce nitrate has been used for powder coating since this highly soluble salt distributes evenly once the solvent is evaporated, obtaining $\mathrm{CeO}_{2}$ after calcination [27].

In Duh et al. [28], pellets of pressed zirconia, either mixed with $\mathrm{CeO}_{2}$ or $\mathrm{Y}_{2} \mathrm{O}_{3}$ by the coprecipitation method, were infiltrated in the green state with $\mathrm{Y}$ nitrate and Ce nitrate solutions, respectively, and the properties of the resulting materials were compared, mainly in terms of fracture toughness and aging behavior. Unfortunately, no information was provided on the strength, the actual yttria and ceria contents, or their distribution in the final materials. Finally, it was shown in a previous communication that infiltration of dental posts in the pre-sintered state with Ce nitrate did not reduce the strength [29].

In the present work, we investigate processing conditions for the co-doping of 3Y-TZP with Ce by liquid infiltration with the objective of increasing significantly the aging resistance without affecting negatively mechanical properties. For doing so, we describe the influence of several Ce solution concentrations, pre-sintering and final sintering temperatures on microstructure, processability and mechanical properties. 


\section{Materials and methods}

\subsection{Material preparation}

3Y-TZP spray-dried TZ-3YSB-E powders (Tosoh corp.) were isostatically pressed into cylindrical rods at $200 \mathrm{MPa}$ during $10 \mathrm{~min}$. The green body was then pre-sintered in air in a tubular furnace with heating/cooling ramps of $3 \% \mathrm{~min}$ and dwell times of one hour at $700{ }^{\circ} \mathrm{C}$ (to evacuate processing additives) and at the final pre-sintering temperature. In a preliminary study, $1100{ }^{\circ} \mathrm{C}$, $1200{ }^{\circ} \mathrm{C}$ and $1300{ }^{\circ} \mathrm{C}$ temperatures were selected for pre-sintering, while the additional temperature of $1150{ }^{\circ} \mathrm{C}$ was later incorporated for process optimization. Nonetheless, results will be presented altogether for the four pre-sintering temperatures, labeling the four conditions as "1100", "1150", "1200" and " $1300 "$ in order of increasing temperature. The pre-sintered rods were cut into discs of about $9.5 \mathrm{~mm}$ in diameter and $2.2 \mathrm{~mm}$ in thickness using a diamond disc (Struers Cutoff Diamond Wheel). The discs were ground (Struers MD-Piano 220) and washed several times with distilled water in ultrasonic bath. This ground and clean state can be reasonably compared to the condition of soft-machined prosthesis.

Liquid solutions were prepared by mixing Ce III Nitrate Hexahydrate (Alfa Aesar) at prescribed concentrations (50 wt $\%$ and $75 \mathrm{wt} \%)$ in ethanol $\left(\mathrm{C}_{2} \mathrm{H}_{5} \mathrm{OH}\right)$, although it was later proved that similar results could be obtained by using distilled water as a solvent. The letters $L$ and $H$ (low and high concentration, respectively) will be added to the pre-sintering temperature codes to refer to the two concentrations.

Infiltration of the pre-sintered blanks was carried out at ambient pressure by soaking the discs into the infiltrating solutions for a fixed time of two hours. The beakers containing the infiltrating solution were periodically stirred to expose both discs faces with direct contact with the solution. Initially, the infiltration was performed both at room temperature and at the solution boiling temperature (by recirculating the solution with a Soxhlet heater/condenser), though no significant 
influence of this parameter could be appreciated, so only results for room temperature infiltration will be reported. After infiltration, the surface of the samples was rapidly dried from the solution in excess with clean laboratory paper and accommodated in vertical position on an alumina boat, avoiding contact between samples. The solvent was evaporated in an oven at around $60{ }^{\circ} \mathrm{C}$ and the specimens were later sintered with $3{ }^{\circ} \mathrm{C}$ heating/cooling rates and dwell time of 2 hours at $1450{ }^{\circ} \mathrm{C}$. A set of non-infiltrated specimens was also directly sintered under the same conditions, obtaining the reference material, which will be referred to as-sintered, "AS".

Some sets of specimens pre-sintered at $1150{ }^{\circ} \mathrm{C}$ and infiltrated with $50 \mathrm{wt} \%$ solution, which showed good overall properties, were sintered both at the reference sintering temperature $\left(1450{ }^{\circ} \mathrm{C}\right)$ and at higher temperatures $\left(1550{ }^{\circ} \mathrm{C}\right.$ and $\left.1600{ }^{\circ} \mathrm{C}\right)$. The objective was to evaluate the effect of increasing the grain size on transformability and resistance to LTD after the addition of Ce. The three materials compared here are labeled "S1450" (formerly named "1150L"), "S1550" and "S1600", in order of increasing sintering temperature.

After sintering, the samples were ground and polished down to a superficial roughness of less than $0.02 \mu \mathrm{m}$. The surface material layer removed during preparation of the samples was of about $15 \mu \mathrm{m}$. For cross-sectional analysis, fully sintered non-polished discs were cut along the diameter with a diamond cutting disc and the section was ground and polished with diamond films using a tripod fixture to minimize edge effects.

\subsection{Characterization}

Density and apparent porosity were measured by Archimedes' method at the sintered and presintered states, according to the guidelines of ASTM C 20-00 standard [30]. Apparent porosity is defined as the open porosity permeable to distilled water. Pore size was estimated at the pre-sintered condition by mercury intrusion porosimetry (MIP) employing a Micrometrics AutoPore IV 9500. The Washburn model, which considers pores of cylindrical geometry and is widely employed in 
this technique, was applied in the calculation of pore diameter. The technique actually measures the largest entrance towards a pore rather than the real pore size, giving so smaller values than the real ones. Although the real pore shape is quite different from a cylinder, especially at low-densification states, this technique gives generally good and reproducible results [31]. The surface of washed blanks was finally imaged by scanning electron microscopy (SEM) with a JEOL JSM 6400.

The $\mathrm{CeO}_{2}$ content profile was measured by Wavelength Dispersive X-Ray Spectrometry (WDS) with an electron microprobe (Cameca sx50) at a voltage of $15 \mathrm{kV}$ along the polished crosssection of sintered discs. Qualitatively similar results were obtained by using Energy-Dispersive Xray Spectroscopy (EDS). The microstructure was characterized on polished samples after thermal etching $\left(1350^{\circ} \mathrm{C}, 1 \mathrm{~h}\right)$ by imaging the specimens in the scanning electron microscope (SEM) (JEOL JSM 6400 or Zeiss Neon 40). Grain size was measured by the linear intercept method.

To evaluate the hydrothermal aging resistance, several polished specimens per condition were exposed to accelerated aging in autoclave at $134{ }^{\circ} \mathrm{C}$ and 2 bar water vapor pressure during $30 \mathrm{~h}$. This degradation time was chosen to be representative of more than an average implant life, since according to the degradation kinetics described in Ref. [32] it roughly compares to 60 years in vivo, (note that this equivalence holds only for stress-free materials). X-Ray Diffraction (XRD) patterns were collected before and after the exposure with a Bruker D8 Advance diffractometer using $\mathrm{Cu}$ $\mathrm{K} \alpha$ radiation and $\theta / 2 \theta$ configuration. In this way, the monoclinic phase content $\left(\mathrm{V}_{\mathrm{m}} \%\right)$ could be determined using the equation proposed by Toraya et al. [33], giving a comparable measure of the aging resistance.

Biaxial strength was measured in a ball on three ball configuration by employing an Instron 8562 servohydraulic testing machine. The maximum biaxial stress at the centre of the tensile face was calculated with the equation proposed by Fett et al. [34]. The ball diameter used in this set-up was of $6 \mathrm{~mm}$ and the crosshead loading rate was adapted according to the specimen thickness, in order to generate a load rate in the sample of approx. $23 \mathrm{MPa} / \mathrm{s}$. 
Indentation fracture (IF) toughness was estimated using a Vickers indenter and a load of $10 \mathrm{~kg}$ (HV10) on the polished specimens. This indentation induces four symmetrical Palmqvist cracks in 3Y-TZP, which were measured by laser scanning confocal microscopy (LSCM). Several equations have been proposed for the calculation of the IF toughness, leading to substantially different results, but all of them involve hardness, elastic modulus and the ratio $c / a$, where $\mathrm{c}$ is the distance between the center of the indentation and the extremity of the crack and $a$ is half of the diagonal of the indentation mark. Here, the equation proposed by Niihara et al. [35] was employed in the calculation. However, since it was observed that in some of the compositions indentation cracks were not exactly of Palmqvist type, the $c / a$ ratio is also reported as a direct measure of the resistance to cracking by indentation. To get a more complete comparison among similar materials, the shape of the induced cracks was also observed by LSCM on the fracture surface of indented discs broken under biaxial loading. An artificial degradation exposure of $10 \mathrm{~h}$ was applied to mark the indentation crack profile, as detailed in Ref. [36]. Micro-Raman spectroscopy was performed (Horiba Jobin-Yvon LabRAM HR 800) by scanning with a $532 \mathrm{~nm}$ solid state diode laser across an indentation crack, at a fixed distance of $50 \mu \mathrm{m}$ from its tip, with steps of $1 \mu \mathrm{m}$. By applying the equation proposed by Katagiri [37], the amount of monoclinic phase can be estimated locally, so the transformability can be compared. Vickers hardness was measured using both $10 \mathrm{~kg}$ and $500 \mathrm{~g}$ loads.

\subsection{Statistical analysis}

One-way analysis of variance (ANOVA) with a Tukey post-hoc test was employed in the statistical analysis for all the tests with sample size greater than 5, excluding XRD, WDS and Raman data. The software Minitab was employed in the analysis, where normality of populations was reasonably assumed and p-value was set at 0.05 . Mean values plus standard deviations are 
presented in the results, while letters on the columns charts show the statistically significant differences.

\section{Results}

The aspect of the $1100{ }^{\circ} \mathrm{C}$ pre-sintered blank surface after grinding is shown in Figure 1, together with the MIP curve, which shows that the pore size diameter is concentrated around 100 $\mathrm{nm}$ in this condition. In Figure 2, density and apparent porosity are presented for the different presintering temperatures and $50 \mathrm{wt} \%$ Cerium nitrate solution. Since the actual content of Ce was impossible to determine a priori, the value of $6,10 \mathrm{~g} / \mathrm{cm}^{3}$, which corresponds to the theoretical density of 3Y-TZP, was considered as the theoretical density in all the cases. Significantly different densities and porosities were found according to the pre-sintering temperature, while the sintered density did not change noticeably for infiltrated samples. Similar results were found for these parameters by using the solution with $75 \mathrm{wt} \%$ concentration of solute. After drying the samples, rests of $\mathrm{CeO}_{2}$ powder were found on the surface of samples and in the boat, meaning that certain amount of salt could escape from the preform when considerable quantities of gases are formed during the decomposition process. Sintered parts that had been infiltrated had a pale yellowish color, being the coloration more significant for lower pre-sintering temperatures and not perceptible for the 1300 condition.

The WDS results are shown in Figure 3, where the profile obtained from the cross-sections is an average of 4 measures and the first point corresponds to a depth of less than $20 \mu \mathrm{m}$ below the outer non polished surface of the disc while the last point corresponds to the sample center, at approximately $1 \mathrm{~mm}$ depth. Measurements taken on the outer disc surface were only approximate due to the effect of roughness on the probe signal, so they are not reported. The WDS profiles show that $\mathrm{CeO}_{2}$ is present after infiltration and sintering with a continuous distribution at the scale length analyzed, with higher content close to the surface. 
The resistance to hydrothermal aging for the different pre-sintering treatments is compared in Figure 4 in terms of superficial monoclinic content calculated from the XRD spectra after artificial degradation. These results show a strong enhancement of aging resistance when significant amounts of $\mathrm{Ce}$ are added. The XRD patterns of some selected aged and non-aged material conditions are shown in Figure $\mathrm{S} 2$ of the supporting information, where the effect of aging on the AS samples can be compared and the similarity between the non-degraded AS material and the aged specimens with higher $\mathrm{CeO}_{2}$ content can be appreciated. Patterns of pre-sintered specimens are not presented since there is no appreciable difference with respect to the non-aged AS, meaning that at the pre-sintered states the material is fully tetragonal, although minor amounts of cubic phase may be present.

The SEM pictures in Figure 5 show an example of change in microstructure associated with Ce co-doping in two of the infiltration conditions. In the histogram, the grain size measured by the intercept method is compared, showing that the microstructure is significantly modified by the presence of Ce. More pictures can be found in the supporting information.

IF toughness is reported in the histogram of Figure 6 . The $c / a$ ratio is plotted on the chart to the right as a function of the $\mathrm{CeO}_{2}$ content measured close to the surface ( $\sim 20 \mu \mathrm{m}$ below the surface) by WDS. Increasing $c / a$ ratios correspond to a decrease in IF toughness. These results show that IF toughness is significantly affected by the infiltration for certain conditions. Vickers hardness values of 13.0 $\pm 0.1 \mathrm{GPa}$ were measured both for AS and for infiltrated samples.

Mean values of biaxial strength $\left(\sigma^{*}\right)$ are reported in the first histogram of Figure 7 . For the specimens with high $\mathrm{CeO}_{2}$ contents a slight decrease in strength is appreciated, otherwise no significant drop is observed. After hydrothermal ageing for $30 \mathrm{~h}$, a tendency to a minor decrease in biaxial strength was recorded for all the samples, though the difference was not statistically significant.

The variation of the $1150 \mathrm{~L}$ samples properties with increasing final sintering temperatures is reported in Table 1. A clear increase in grain size is observed for S1550 and S1600 with respect to 
S1450 samples (see the supporting information for micrographs). The $\mathrm{CeO}_{2}$ content was in this case measured by EDS, so it is only reported for comparison among these three conditions. The monoclinic content is also quantified in Table 1, meanwhile examples of XRD spectra after artificial degradation can be found in the supporting information. The aging behavior was clearly worsened by sintering at higher temperatures. By contrast, IF toughness values reported in Table 1 show significant improvements for S1550 and S1600 materials. The shape of the indentation cracks below the surface can be appreciated on the fracture surfaces presented in Figure 8 . The crack shape of co-doped samples with pre-sintering parameters other than the $1150 \mathrm{~L}$ one varied according to $\mathrm{CeO}_{2}$ content. Palmqvist cracks similar to the one shown in Fig. 8 for AS were obtained for low $\mathrm{CeO}_{2}$ contents, while the shape was similar to the one for $\mathrm{S} 1450$ for intermediate contents and deeper cracks with nearly half-penny shape were observed for higher amounts of ceria.

The monoclinic content calculated from the Raman spectra obtained by scanning across an indentation crack at $50 \mu \mathrm{m}$ from the crack tip is shown in Figure 8. The thickness of the transformed region and the amount of monoclinic phase $\left(\mathrm{V}_{\mathrm{m}} \%\right)$ give an idea of the transformability of the tetragonal phase, which increases with higher sintering temperatures. The monoclinic fraction is meant only for qualitative comparison, since the conical laser sampling volume comprises several micrometers below the surface, where the transformed fraction is not constant [38].

\section{Discussion}

This work approaches in a systematic way the development of and easy and inexpensive method for increasing the surface stability of 3Y-TZP implants. It was proved that tailored quantities of $\mathrm{CeO}_{2}$ could be infiltrated into the ceramic part after soft machining, without altering significantly the processing method. 


\subsection{Density}

In the pre-sintered state, significant differences in density were observed in the range of temperature studied, from approx. $50 \%$ for $1100{ }^{\circ} \mathrm{C}$ to approx. $90 \%$ for $1300{ }^{\circ} \mathrm{C}$. Moreover, nearly all the porosity was open to water infiltration for all conditions with the exception of the $1300{ }^{\circ} \mathrm{C}$ pre-sintering temperature, where the difference between total porosity $(100-90.7=9.3 \%)$ and apparent porosity $(4.7 \%)$ was significant. It means that a big fraction of the porosity is closed or not accessible to boiling water for this temperature. After final sintering, the density was relatively close $(\geq 97 \%)$ to the theoretical full density of $3 \mathrm{Y}$-TZP, independently of the pre-sintering temperature.

\section{2 $\mathrm{CeO}_{2}$ profiles and microstructural aspects}

By increasing the concentration of the infiltration solution, considerably higher quantities of $\mathrm{CeO}_{2}$ doping are obtained. The same tendency is observed when the pre-sintering temperature is decreased, that is, when total and open porosity reaches higher values. The highest concentration of ceria $(7.8 \mathrm{~mol} \%)$ was detected close to the surface of $1100 H$ samples, which had the highest porosity at the pre-sintered state. Practically no Cerium was introduced with the $1300{ }^{\circ} \mathrm{C}$ presintering treatment since the open porosity is small at this temperature. A direct correspondence exists between the $\mathrm{CeO}_{2}$ content measured after sintering and pre-sintered porosity. Therefore, these results are consistent with the apparent porosity results shown above. On the other hand, it can be appreciated that higher quantities of $\mathrm{CeO}_{2}$ result in greater differences between the center and the surface, i.e. the concentration profile becomes steeper.

Certain variability exists between samples processed under the same conditions, since differences in the $\mathrm{CeO}_{2}$ content were found at the same depth from the surface. These differences, which could be related to non-uniformities during drying and salt decomposition, were smaller than $1 \mathrm{~mol} \%$. In order to reduce this variability, the drying conditions after infiltration were changed 
avoiding the contact between sample surface and porous setters or supports during this process. Similar precautions may be followed during salt decomposition, since melting occurs before the elimination of hydration water.

The microstructure is progressively affected by the introduction of $\mathrm{CeO}_{2}$, obtaining slightly bigger grain sizes with respect to the reference material. The increase in grain size is small as compared to Ce-TZP sintered with prealloyed powders containing $10-12 \mathrm{~mol} \% \mathrm{CeO}_{2}$, where 3-5 $\mu \mathrm{m}$ are usually reported [39]. Therefore, alloying with Ce by infiltration has the relevant outcome of obtaining smaller grain sizes compared with sintering from prealloyed powders. The slight grain size increase associated with Ce doping may be related to a reduction in the solute drag mechanism active in Y-TZP, where yttria segregates at grain boundaries operating a drag force against grain boundary mobility. On the contrary, in Ce-TZP the segregation has not been observed, meanwhile it seems to be present but less active in Ce-Y-TZP [40,41]. According to the ternary phase diagram $\mathrm{Y}_{2} \mathrm{O}_{3}-\mathrm{CeO}_{2}-\mathrm{ZrO}_{2}$ at $1450{ }^{\circ} \mathrm{C}$ [42], the addition of $\mathrm{CeO}_{2}$ to $3 \mathrm{Y}-\mathrm{TZP}$ leads to a moderate increase in the fraction of cubic phase at equilibrium. At the same time, the miscibility gap becomes wider, meaning that the tetragonal phase contains less yttria (and more ceria) and the cubic phase contains more yttria (and less ceria) than for 3Y-TZP. Yttria will tend to move from the tetragonal to the cubic grains and ceria will tend to diffuse mostly into the tetragonal ones. Therefore, the observed grain growth may be related to both the reduction of yttria in tetragonal grains, where the solutiondrag mechanism would be less significant, and the generation of more yttria-rich cubic grains, which have faster growth kinetics. To support this idea, the progressive development of a bimodal grain distribution can be appreciated from micrographs, which is often observed in Y-TZP after long sintering times or at higher temperatures [43]. Nonetheless, with these sintering conditions we are still far from the equilibrium and the conversion from tetragonal to cubic phase needs the formation of highly concentrated regions where the tetragonal distortion is reduced enough to nucleate the new phase [44]. Hence, the amount of cubic phase will be sensitive to the sintering 
time at this temperature $[45,46]$. The dopants in excess are probably highly concentrated along grain boundaries, which can accommodate more stabilizer, and the tetragonal phase is likely to be supersaturated. The development of two types of supersaturated tetragonal grains (one more and one less doped) instead of the separation into cubic and tetragonal phases has also been reported [47].

\subsection{Aging resistance}

$\mathrm{CeO}_{2}$ addition increases significantly the aging resistance: after $30 \mathrm{~h}$ of artificial degradation the amount of monoclinic phase is still practically zero for some of the infiltrated specimens. Here the material has been considered hydrothermally stable for the processing conditions where the transformation falls below $5 \mathrm{~V}_{\mathrm{m}} \%$, which corresponds with the limit detectable by XRD. These conditions are those where the superficial $\mathrm{CeO}_{2}$ content is at least roughly $3 \mathrm{~mol} \%$. The improvement of aging behavior may be ascribed to the presence of the additional stabilizer, which is not affected by the diffusion of water species. Moreover, the partial diffusion of yttria into cubic grains and ceria into the tetragonal ones may reduce the number of vacancies in the tetragonal phase.

A shift of the 101 tetragonal peak $\left(2 \theta \sim 30.2^{\circ}\right)$ towards the left of the XRD pattern, which corresponds to the increase in the unit cell dimension that is normally associated with Ce doping in zirconia [48], was observed in co-doped samples (spectra available in the supporting information). This evidence suggests a method for measuring the quantity of $\mathrm{CeO}_{2}$ at the surface after infiltration, based on the 101 peak position. Modeling of the calibration curve would require specimens with controlled compositions and free from stresses at the surface.

\subsection{Mechanical properties}

Vickers hardness values were not affected by the Ce infiltration, probably in relation to the limited modification of the microstructure. On the other hand, a significant decrease in IF toughness 
is observed for the specimens with high $\mathrm{CeO}_{2}$ contents; the drop can be as much as $1 \mathrm{MPaVm}$ with respect to the control material. This aspect is related to the over-stabilization of the tetragonal phase due to the co-doping and the possible increase in the amount of cubic phase. For other processing conditions where hydrothermally stable materials are obtained, the decrease is smaller (about 10\%), e.g. $1100 \mathrm{~L}, 1150 \mathrm{~L}, 1200 \mathrm{H}$. These are therefore the optimum infiltration conditions, and correspond to superficial $\mathrm{CeO}_{2}$ contents between 3 and $4.6 \mathrm{~mol} \%$. For lower concentrations, the material still suffers from LTD. Since the concentration of $\mathrm{CeO}_{2}$ only changes slightly along the depth of the induced cracks $\left(120 \mu \mathrm{m} \sim 0.06\right.$ norm. depth), the $\mathrm{CeO}_{2}$ gradient effects on IF toughness should be of minor importance, so the measured values can be assumed as representative of the average IF toughness in the near-surface region.

Figure 6 clearly shows that as $\mathrm{CeO}_{2}$ content increases, there is an increase in the $c / a$ ratio, meaning that the IF toughness of the near-surface region is reduced. However, it may be kept close to typical values of $3 \mathrm{Y}$-TZP by limiting the $\mathrm{CeO}_{2}$ doping below $4 \mathrm{~mol} \%$. In this sense, the effect of adding Ceria stabilizer on the fracture toughness of 3Y-TZP is similar as for yttria in Y-TZP, but the change per mol\% of stabilizer is smaller.

The biaxial strength shows values above $1000 \mathrm{MPa}$ for all the infiltrated conditions, being only slightly lower than the reference material. This result is important because, despite the "nearsurface" IF toughness being slightly decreased by the stabilizer addition, the biaxial strength is still close to typical values of 3Y-TZP in most of the treatments. From this observation, it can be concluded that the optimal infiltration conditions do not introduce large processing defects or impair the sintering behavior of $3 \mathrm{Y}$-TZP. For the rest of the infiltration conditions, a weak correlation exists between the observed drop in strength and the measured IF toughness. Nevertheless, the large scatter in the results, the graded composition along specimen thickness and the changes in the cracks shape observed with increasing $\mathrm{CeO}_{2}$ content (see Fig. 8 and next section) 
makes the correlation not straightforward. However, the clear result is that the reliability in terms of strength for infiltrated specimens under optimum conditions is very close to standard 3Y-TZP.

\subsection{Effect of the sintering temperature}

Among all the tested materials, $1150 L$ specimens were selected to study the effect of sintering temperature since these were resistant to LTD, their IF toughness was only slightly affected and their biaxial strength unchanged if compared with the reference material. The main objective was to assess if the decrease in "near-surface" IF toughness could be avoided by increasing the sintering temperature. Higher sintering temperatures would increase the grain size and promote phase separation, favoring t-m transformation and so enhancing fracture toughness [49], but the degradation kinetics may be negatively affected [50]. On the other hand, by increasing the grain size, other toughening mechanisms may be operative, like crack deflection and microcracking.

For the higher sintering temperatures, the average grain size was significantly increased, as reported in Table 1. At the same time, Vickers hardness registered a slight decrease. Taking into account the limited precision of the EDS technique used in this case, no significant difference in the $\mathrm{CeO}_{2}$ content was measured. IF toughness was considerably increased for the $\mathrm{S} 1600$ condition, obtaining values even higher than for the reference AS condition (Table 1). These results can be rationalized in terms of the enhancement of $\mathrm{t}-\mathrm{m}$ transformability with temperature, which can also be appreciated from the width of the transformed zone and the amount of monoclinic phase near the crack in Fig. 8. The relation between transformability and fracture toughness is not straightforward, though. For example, it can be observed that $\mathrm{S} 1550$ samples had identical $\mathrm{K}_{\mathrm{IC}}$ as $\mathrm{AS}$, in spite of apparent less transformability (Fig. 8), meaning that other toughening mechanisms may play a minor role. Besides the effect of the grain size increase on transformability, an influence of the sintering temperature on the Ce distribution at the microscopic level has to be considered. Since Ce starts diffusing from the pores, a local Ce concentration gradient is expected at low sintering 
temperature, while better homogenization should result from higher temperatures thanks to the increased diffusion coefficient, which suggests an increase in tetragonal stability. Nevertheless, the system is getting closer to the equilibrium at higher temperature and the stabilizers are likely to segregate more at the grain boundaries [41,51], with the formation of increasing fractions of cubic phase that would favor the destabilization of the neighboring tetragonal grains [46]. These conflicting behaviors cannot be used as an argument unless the Ce local concentration is studied with high resolution techniques, which is out of the scope of the present study.

In order to understand the change in IF toughness it is important to observe the shape of indentation cracks. In Fig. 8 it can be clearly observed that Palmqvist cracks are obtained in AS samples and that the effect of Ce addition is to change the dimensions and shape of the cracks, which extend below the plastic zone. This change in shape has been observed before, either as the indentation load is increased or as the fracture toughness decreases [52]. The Palmqvist shape is recovered in the S1550 and in S1600 samples, being the cracks in the latter even less deep than in AS material, which is in agreement with the higher IF toughness measured.

In spite of the higher IF toughness of S1600, this material shows a slight lower biaxial strength (see Table 1). This may be explained considering the general relation between strength and fracture toughness of zirconia-based ceramics [53]. When transformation toughening increases, the strength is also improved if the defect size is unchanged. However, when the transformation stress becomes relatively small and the transformed volume is not only confined near sharp cracks, the transition between the flaw-limited to the transformation-limited strength regimes takes place [54]. Nevertheless, in the present case there was no evidence of extensive transformation at the surface after testing and the transformation thickness near the crack was lesser (S1550) or comparable (S1600) to the reference material, suggesting that probably the increase of defects size may explain the drop in fracture strength. 
At the same time, for S1550 and S1600 samples the resistance to degradation is lost, obtaining similar amounts of monoclinic phase as for AS samples. Therefore, $1450{ }^{\circ} \mathrm{C}$ is also the optimum sintering temperature for achieving higher strength in the infiltrated material, where the decrease in IF toughness cannot be fully compensated without affecting negatively hydrothermal stability, biaxial strength and hardness.

\subsection{Clinical implications and perspectives}

The proposed method is directly applicable by the technician or practitioner to the preparation of aging resistant zirconia dental parts in the dental laboratory. In practical terms, it implies the pressureless dipping of shaped parts pre-sintered at $1150{ }^{\circ} \mathrm{C}$ into a $50 \mathrm{wt} \%$ Cerium Nitrate solution, prior to firing. The potential impact is to solve the problem of hydrothermal aging in zirconia dental materials, moving towards a new generation of reliable all-ceramic dental systems, where esthetical and allergic problems related to the use of metals are avoided. The major drawback of this procedure is represented by the slight color change, which is not an issue in the case of implants and abutments but might require the adaptation of the veneering procedure for achieving the same tonality in visible parts. Future studies may aim to control the infiltration profile to confine the codoping to a thin superficial layer, with the goal of compensating the observed small reduction in IF toughness.

\section{Conclusions}

A simple method for modifying dental zirconia to improve its long-term superficial stability has been presented. This is based on the infiltration of the pre-sintered 3Y-TZP machined part with Ce salt solutions, and can be easily adapted to the dry-processing of dental applications.

It has been shown that hydrothermal degradation can be remarkably reduced by selecting specific pre-sintering temperatures and optimized solutions. An optimal compromise in properties is 
achieved for $\mathrm{CeO}_{2}$ contents around $3 \mathrm{~mol} \%$ at the surface. If the sintering temperature for this composition is increased, fracture toughness can be improved up to values higher than for the reference 3Y-TZP; however, a slight decrease in strength and poor LTD resistance are obtained in this case, meaning that the standard $1450{ }^{\circ} \mathrm{C}$ sintering temperature provides better overall properties for the Cerium infiltrated zirconia with the composition studied.

\section{Acknowledgements}

This work was supported by Ministry of Economy and Competitiveness (MINECO) under the project ref. MAT2011-23913 and by Government of Catalonia under the project ref. 2014SGR0130. Erik Camposilvan acknowledges Universitat Politècnica de Catalunya for the grant FPU-UPC. 


\section{References}

[1] Chevalier J, Gremillard L, Deville S. Low-Temperature Degradation of Zirconia and Implications for Biomedical Implants. Annu Rev Mater Res 2007;37:1-32.

[2] Miyazaki T, Nakamura T, Matsumura H, Ban S, Kobayashi T. Current status of zirconia restoration. J Prosthodont Res 2013;57:236-61.

[3] Denry I, Holloway JA. Ceramics for Dental Applications: A Review. Materials (Basel) 2010;3:351-68.

[4] Clarke IC, Manaka M, Green DD, Williams P, Pezzotti G, Kim Y-H, et al. Current status of zirconia used in total hip implants. J Bone Joint Surg Am 2003;85-A Suppl:73-84.

[5] Zirconia ceramic heads for modular total hip femoral components: advice to users on resterilization. Safety Notice MDA SN 9617. n.d.

[6] Piconi C, Maccauro G, Pilloni L, Burger W, Muratori F, Richter HG. On the fracture of a zirconia ball head. J Mater Sci Mater Med 2006;17:289-300.

[7] Shah K, Holloway J a, Denry I. Effect of coloring with various metal oxides on the microstructure, color, and flexural strength of 3Y-TZP. J Biomed Mater Res B Appl Biomater 2008;87:329-37.

[8] Denry I, Kelly JR. State of the art of zirconia for dental applications. Dent Mater 2008;24:299-307.

[9] Hisbergues M, Vendeville S, Vendeville P. Zirconia: Established facts and perspectives for a biomaterial in dental implantology. J Biomed Mater Res B Appl Biomater 2009;88:519-29. 
[10] Tsubakino H, Sonoda K, Nozato R. Martensite transformation behaviour during isothermal ageing in partially stabilized zirconia with and without alumina addition. J Mater Sci Lett $1993 ; 12: 196-8$.

[11] Oblak C, Verdenik I, Swain M V, Kosmac T. Survival-rate analysis of surface treated dental zirconia (Y-TZP) ceramics. J Mater Sci Mater Med 2014;25:2255-64.

[12] Siarampi E, Kontonasaki E, Andrikopoulos KS, Kantiranis N, Voyiatzis G a, Zorba T, et al. Effect of in vitro aging on the flexural strength and probability to fracture of Y-TZP zirconia ceramics for all-ceramic restorations. Dent Mater 2014;30:e306-16.

[13] Cattani-Lorente M, Scherrer SS, Durual S, Sanon C, Douillard T, Gremillard L, et al. Effect of different surface treatments on the hydrothermal degradation of a 3Y-TZP ceramic for dental implants. Dent Mater 2014;30:1136-46.

[14] Lughi V, Sergo V. Low temperature degradation -aging- of zirconia: A critical review of the relevant aspects in dentistry. Dent Mater 2010;26:807-20.

[15] Kelly JR, Denry I. Stabilized zirconia as a structural ceramic: an overview. Dent Mater 2008;24:289-98.

[16] Guo X. Low temperature degradation mechanism of tetragonal zirconia ceramics in water: role of oxygen vacancies. Solid State Ionics 1998;112:113-6.

[17] Li P, Chen I-W, Penner-hahn JE. Effect of Dopants on Zirconia Stabilization-An X-ray Absorption Study: II, Tetravalent Dopants. J Am Ceram Soc 1994;77:1281-8. 
[18] Chevalier J, Gremillard L, Virkar A V., Clarke DR. The Tetragonal-Monoclinic Transformation in Zirconia: Lessons Learned and Future Trends. J Am Ceram Soc 2009;92:1901-20.

[19] Lin J-D, Duh JG. Correlation of mechanical properties and composition in tetragonal CeO2Y2O3-ZrO2 ceramic system. Mater Chem Phys 2003;78:246-52.

[20] Sergo V, Schmid C, Meriani S, Evans AG. Mechanically Induced Zone Darkening of Alumina/Ceria-Stabilized Zirconia Composites. J Am Ceram Soc 1994;77:2971-6.

[21] Hernandez MT, Jurado JR, Duran P, Fierro JLG. Subeutectoid Degradation of YttriaStabilized Tetragonal Zirconia Polycrystal and Ceria-Doped Yttria-Stabilized Tetragonal Zirconia Polycrystal Ceramics. J Am Ceram Soc 1991;74:1254-8.

[22] Boutz MMR, Winnubst AJA, Langerak B, Olde Scholtenhuis R, Kreuwel K, Burggraaf A. The effect of ceria co-doping on chemical stability and fracture toughness of Y-TZP. J Mater Sci 1995;30:1854-62.

[23] Sato T, Ohtaki S, Fukushima T, Endo T, Shimada M. Mechanical propierties and thermal stability of yttria doped tetragonal zirconia polycrystals with diffused ceria in the surface. Mater Res Soc Symp Proc 1987;78:147-54.

[24] Marro FG, Valle J, Mestra a., Anglada M. Surface modification of 3Y-TZP with cerium oxide. J Eur Ceram Soc 2011;31:331-8.

[25] Miyazaki T, Hotta Y, Kunii J, Kuriyama S, Tamaki Y. A review of dental CAD/CAM: current status and future perspectives from 20 years of experience. Dent Mater J 2009;28:4456. 
[26] Glass SJ, Green DJ. Permeability and Infiltration of Partially Sintered Ceramics. J Am Ceram Soc 1999;82:2745-52.

[27] Wattanasiriwech D, Wattanasiriwech S. Preparation and phase development of yttria-doped ceria coated TZP powder. J Mater Sci 2008;43:6473-9.

[28] Duh JG. Liquid infiltration in ZrO2 ceramics. J Mater Sci Lett 1993;12:473-5.

[29] Camposilvan E, Marro FG, Mestra A, Anglada M. Development of a novel zirconia dental post resistant to hydrothermal degradation. IOP Conf Ser Mater Sci Eng 2012;31:012016.

[30] ASTM Standard C 20 - 00: Standard Test Methods for Apparent Porosity, Water Absorption, Apparent Specific Gravity, and Bulk Density of Burned Refractory Brick and Shapes by Boiling Water. West Conshohocken: 2000.

[31] Giesche H. Mercury Porosimetry: A General (Practical) Overview. Part Part Syst Charact 2006;23:9-19.

[32] Chevalier J, Cales B, Drouin JM. Low-Temperature Aging of Y-TZP Ceramics. J Am Ceram Soc 1999;82:2150-4.

[33] Toraya H, Yoshimura M, Somiya S. Calibration Curve for Quantitative Analysis of the Monoclinic-Tetragonal ZrO2 System by X-Ray Diffraction. J Am Ceram Soc 1984;67:C $119-\mathrm{C}-121$.

[34] Fett T, Rizzi G, Esfehanian M, Oberacker R. Simple Expressions for the Evaluation of Stresses in Sphere-Loaded Disks Under Biaxial Flexure. J Test Eval 2010;36:530. 
[35] Niihara K. A fracture mechanics analysis of indentation-induced Palmqvist crack in ceramics. J Mater Sci Lett 1983;2:221-3.

[36] Marro FG, Camposilvan E, Anglada M. Revealing crack profiles in polycrystalline tetragonal zirconia by ageing. J Eur Ceram Soc 2012;32:1541-9.

[37] Katagiri G, Ishida H, Ishitani A. Direct determination by a Raman microprobe of the transformation zone size in $\mathrm{Y} 2 \mathrm{O} 3$ containing tetragonal $\mathrm{ZrO} 2$ polycrystals. In: Somiya $\mathrm{S}$, Yamamoto N, Yanagida H, editors. Adv. Ceram. Vol. 24 Sci. Technol. Zirconia III, Westerville, OH: American Ceramic Society; 1988, p. 537-44.

[38] Pezzotti G. Raman piezo-spectroscopic analysis of natural and synthetic biomaterials. Anal Bioanal Chem 2005;381:577-90.

[39] Tsukuma K, Shimada M. Strength, fracture toughness and Vickers hardness of CeO2stabilized tetragonal ZrO2 polycrystals (Ce-TZP). J Mater Sci 1985;20:1178-84.

[40] Boutz MMR, Winnubst AJA, Burggraaf AJ. Yttria-Ceria Stabilized Tetragonal Zirconia Polycrystals: Sintering, Grain Growth and Grain Boundary Segregation. J Eur Ceram Soc 1994;13:89-102.

[41] Theunissen GSAM, Winnubst a. J a., Burggraaf a. J. Effect of dopants on the sintering behaviour and stability of tetragonal zirconia ceramics. J Eur Ceram Soc 1992;9:251-63.

[42] Huang SG, Vleugels J, Li L, Biest O Van Der, Wang PL. Composition design and mechanical properties of mixed ( $\mathrm{Ce}, \mathrm{Y}$ ) -TZP ceramics obtained from coated starting powders. J Eur Ceram Soc 2005;25:3109-15. 
[43] Gadow R, Kern F. Novel Zirconia-Alumina Nanocomposites Combining High Strength and Toughness. Adv Eng Mater 2010;12:1220-3.

[44] Matsui K, Horikoshi H, Ohmichi N, Ohgai M, Yoshida H, Ikuhara Y. Cubic-Formation and Grain-Growth Mechanisms in Tetragonal Zirconia Polycrystal. J Am Ceram Soc 2003;86:1401-8.

[45] Inokoshi M, Zhang F, De Munck J, Minakuchi S, Naert I, Vleugels J, et al. Influence of sintering conditions on low-temperature degradation of dental zirconia. Dent Mater 2014;30:669-78.

[46] Chevalier J, Deville S, Münch E, Jullian R, Lair F. Critical effect of cubic phase on aging in 3mol\% yttria-stabilized zirconia ceramics for hip replacement prosthesis. Biomaterials 2004;25:5539-45.

[47] Yamashita I, Tsukuma K, Tojo T, Kawaji H, Atake T. Synchrotron X-Ray Study of the Crystal Structure and Hydrothermal Degradation of Yttria-Stabilized Tetragonal Zirconia Polycrystal. J Am Ceram Soc 2008;91:1634-9.

[48] Yashima M, Sasaki S, Yamaguchi Y, Kakihana M, Yoshimura M, Mori T. Internal distortion in $\mathrm{ZrO} 2-\mathrm{CeO} 2$ solid solutions: Neutron and high-resolution synchrotron $\mathrm{x}$-ray diffraction study. Appl Phys Lett 1998;72:182.

[49] Becher PF, Swain M V. Grain-Size-Dependent Transformation Behavior in Polycrystalline Tetragonal Zirconia. J Am Ceram Soc 1992;75:493-502.

[50] Jue JF, Chen J, Virkar A V. Low-Temperature Aging of t'-Zirconia: The Role of Microstructure on Phase Stability. J Am Ceram Soc 1991;74:1811-20. 
[51] Matsui K. Grain-boundary structure and microstructure development mechanism in 2-8 mol\% yttria-stabilized zirconia polycrystals. Acta Mater 2008;56:1315-25.

[52] Lankford J. Threshold microfracture during elastic-plastic indentation of ceramics. J Mater Sci 1981;16:1177-82.

[53] Swain M V, Rose LRF. Strength Limitations of Transformation-Toughened Zirconia Alloys. J Am Ceram Soc 1986;69:511-8.

[54] J. Wang, M. Rainforth RS. The Grain Size Dependence of the Mechanical Properties in TZP Ceramics. In: Meriani S, Palmonari C, editors. Zirconia '88 Adv. Zirconia Sci. Technol., Springer Netherlands; 1989, p. 337-66. 
Figure 1. (L) surface appearance imaged by SEM (scale bar $=500 \mathrm{~nm}$ ) and (R) MIP curve as a function of pore size are shown, as an example, for the $1100{ }^{\circ} \mathrm{C}$ pre-sintered state.

Figure 2. The density and apparent porosity for the pre-sintered state, as well as sintered density after infiltration with $50 \mathrm{wt} \%$ solution, are shown in the column chart. The apparent porosity at the sintered state was $\sim 0$.

Figure 3. WDS $\mathrm{CeO}_{2}$ content: a) in terms of depth normalized by disc thickness, and b) measured near the disc surface. Mean values \pm SD.

Figure 4. Degradation vs. pre-sintering temperature and solution concentration. Mean values \pm SD.

Figure 5. Grain size vs. pre-sintering condition. Pictures $a$ and $b$ show, respectively, the microstructure of $1300 \mathrm{~L}$ and $1100 \mathrm{H}$ materials.

Figure 6. (L) Indentation fracture toughness vs. pre-sintering temperature and solution concentration. (R) Relative indentation crack length $(c / a)$ as a function of the $\mathrm{CeO}_{2}$ content measured at the surface.

Figure 7. Biaxial strength vs. pre-sintering temperature and solution concentration.

Figure 8. Transformability and crack development in AS, S1450, S1550 and S1600 materials. Top: LSCM micrographs of indentation crack surfaces after biaxial breakage. Scale bar $=100 \mu \mathrm{m}$. Bottom: monoclinic content measured by Raman spectroscopy across an indentation crack. The Raman analysis was performed from the polished surface of the sample, as indicated in the diagram. 
Table 1. Properties of AS, S1450, S1550 and S1600 materials (mean values \pm SD). Letters indicate the statistically significant differences.

\begin{tabular}{|c|c|c|c|c|c|c|c|}
\hline Condition & $\begin{array}{c}\text { Sinter. Temp. } \\
\left({ }^{\circ} \mathrm{C}\right)\end{array}$ & $\begin{array}{c}\text { Grain Size } \\
(\mu \mathrm{m})\end{array}$ & $\begin{array}{l}\text { HV10 } \\
(\text { GPa }) \\
\end{array}$ & $\begin{array}{c}\mathrm{CeO}_{2} \\
(\mathrm{~mol} \%) \\
\end{array}$ & $\begin{array}{l}V_{m} \\
(\%)\end{array}$ & $\begin{array}{c}\mathbf{K}_{\mathrm{IC}} \\
\left(\mathrm{MPa} \sqrt{ }_{\mathbf{m}}\right)\end{array}$ & $\begin{array}{c}\sigma^{*}{ }_{\text {в3в }} \\
(\mathrm{MPa})\end{array}$ \\
\hline AS & 1450 & $0.32 \pm 0.03$ & $\underset{\mathrm{a}}{13.0 \pm 0.1}$ & 0 & $42 \pm 24$ & $\underset{\mathrm{a}}{4.9 \pm 0.1}$ & $\begin{array}{c}1616 \pm 74 \\
\mathrm{a}\end{array}$ \\
\hline S1450 & 1450 & $\begin{array}{c}0.34 \pm 0.05 \\
\mathrm{a}\end{array}$ & $\underset{\mathrm{a}}{13.1 \pm 0.2}$ & 2.6 & $0 \pm 2$ & $\underset{\mathrm{b}}{4.5 \pm 0.1}$ & $\begin{array}{c}1587 \pm 148 \\
\text { a, b }\end{array}$ \\
\hline $\mathrm{S} 1550$ & 1550 & $\begin{array}{c}0.64 \pm 0.14 \\
b\end{array}$ & $\begin{array}{c}12.7 \pm 0.2 \\
b\end{array}$ & 2.4 & $34 \pm 15$ & $\begin{array}{c}4.9 \pm 0.2 \\
\mathrm{a}\end{array}$ & $\begin{array}{c}1360 \pm 218 \\
b, c\end{array}$ \\
\hline S1600 & 1600 & $\begin{array}{c}0.78 \pm 0.18 \\
b\end{array}$ & $\begin{array}{c}12.4 \pm 0.1 \\
\mathrm{c}\end{array}$ & 2.2 & $40 \pm 15$ & $\begin{array}{c}5.0 \pm 0.1 \\
\mathrm{a}\end{array}$ & $\begin{array}{c}1320 \pm 112 \\
\mathrm{c}\end{array}$ \\
\hline
\end{tabular}



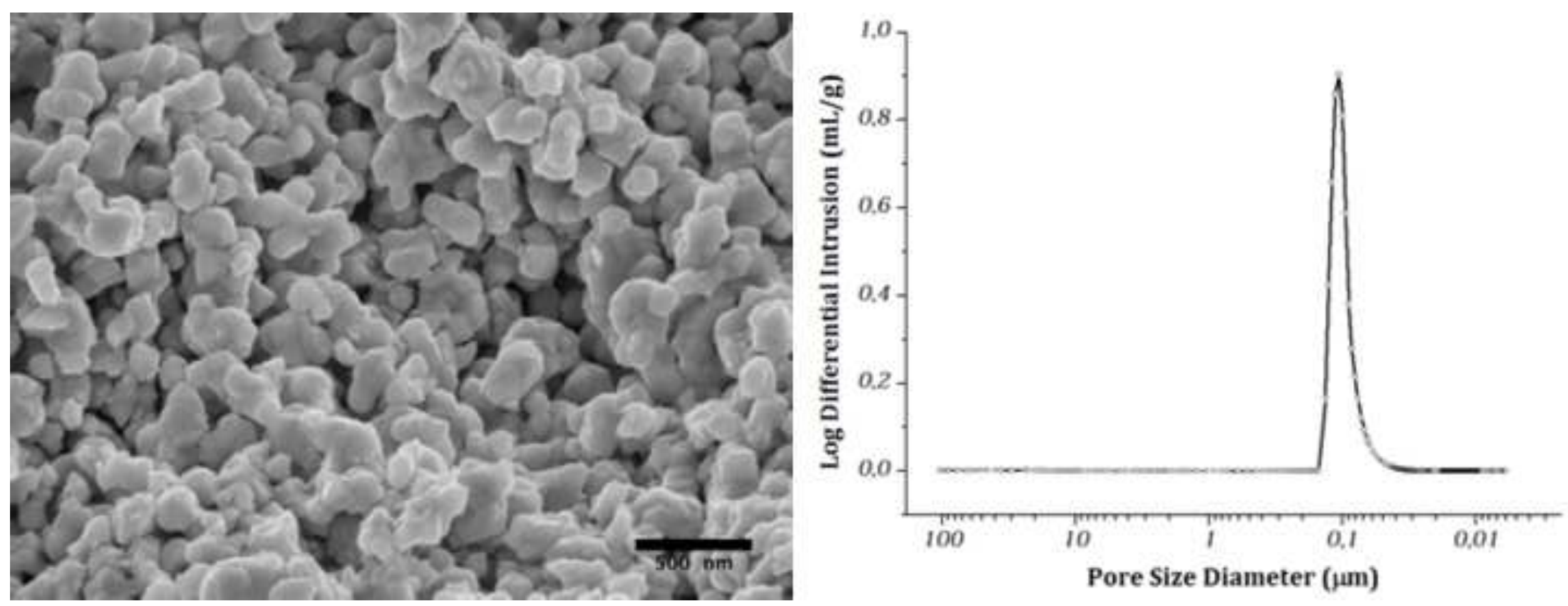


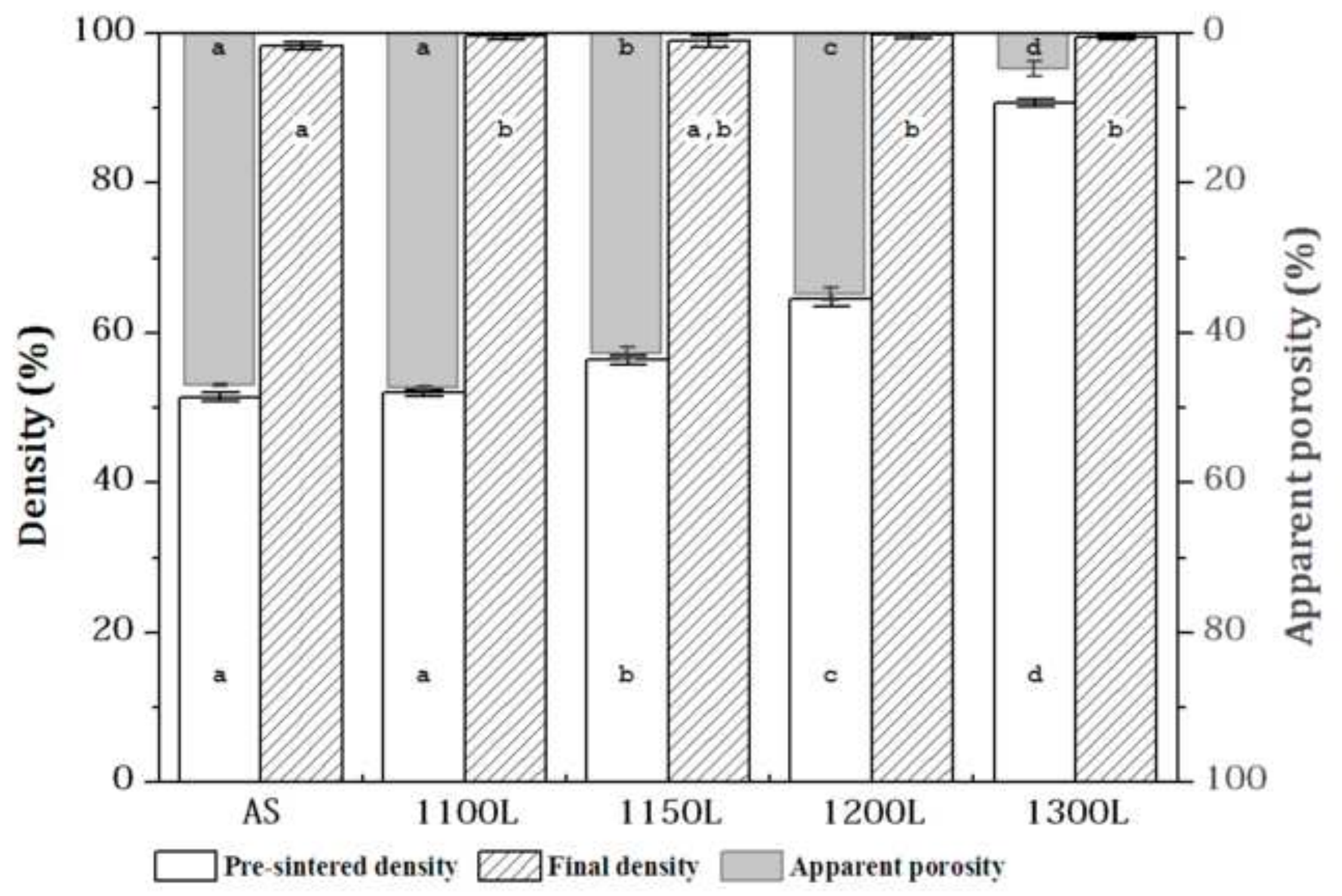



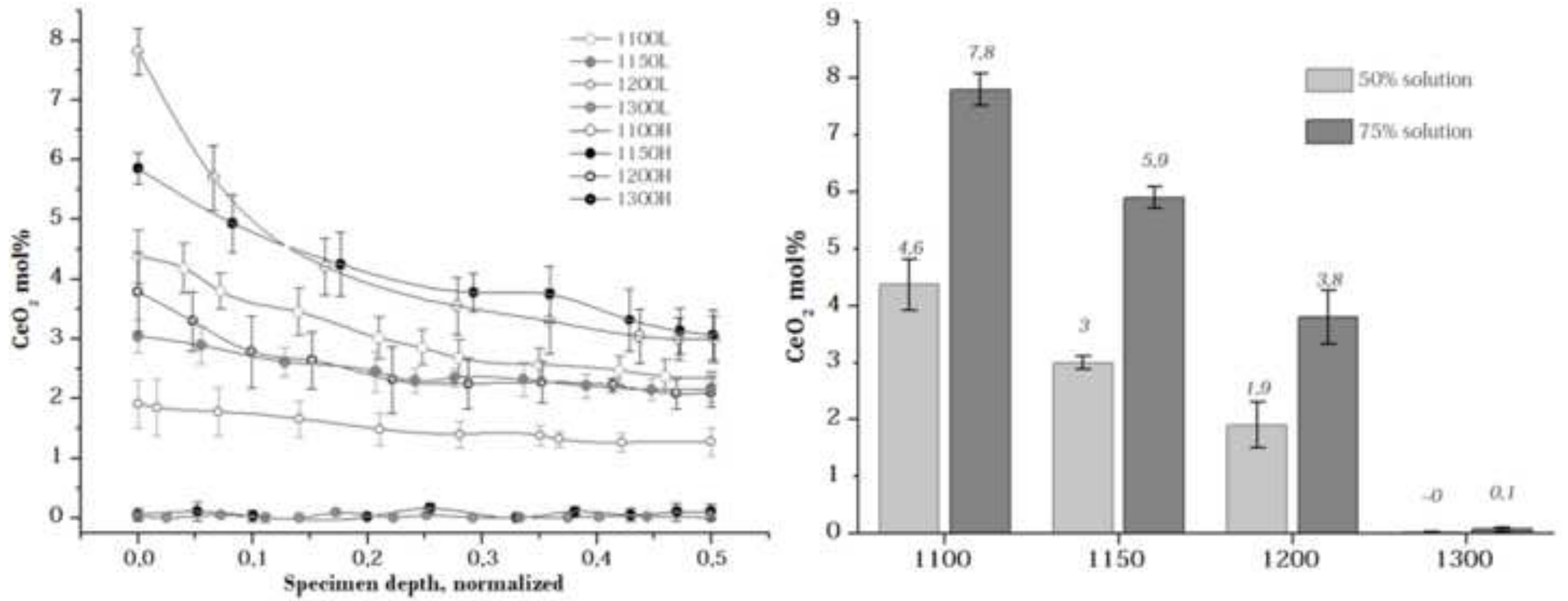


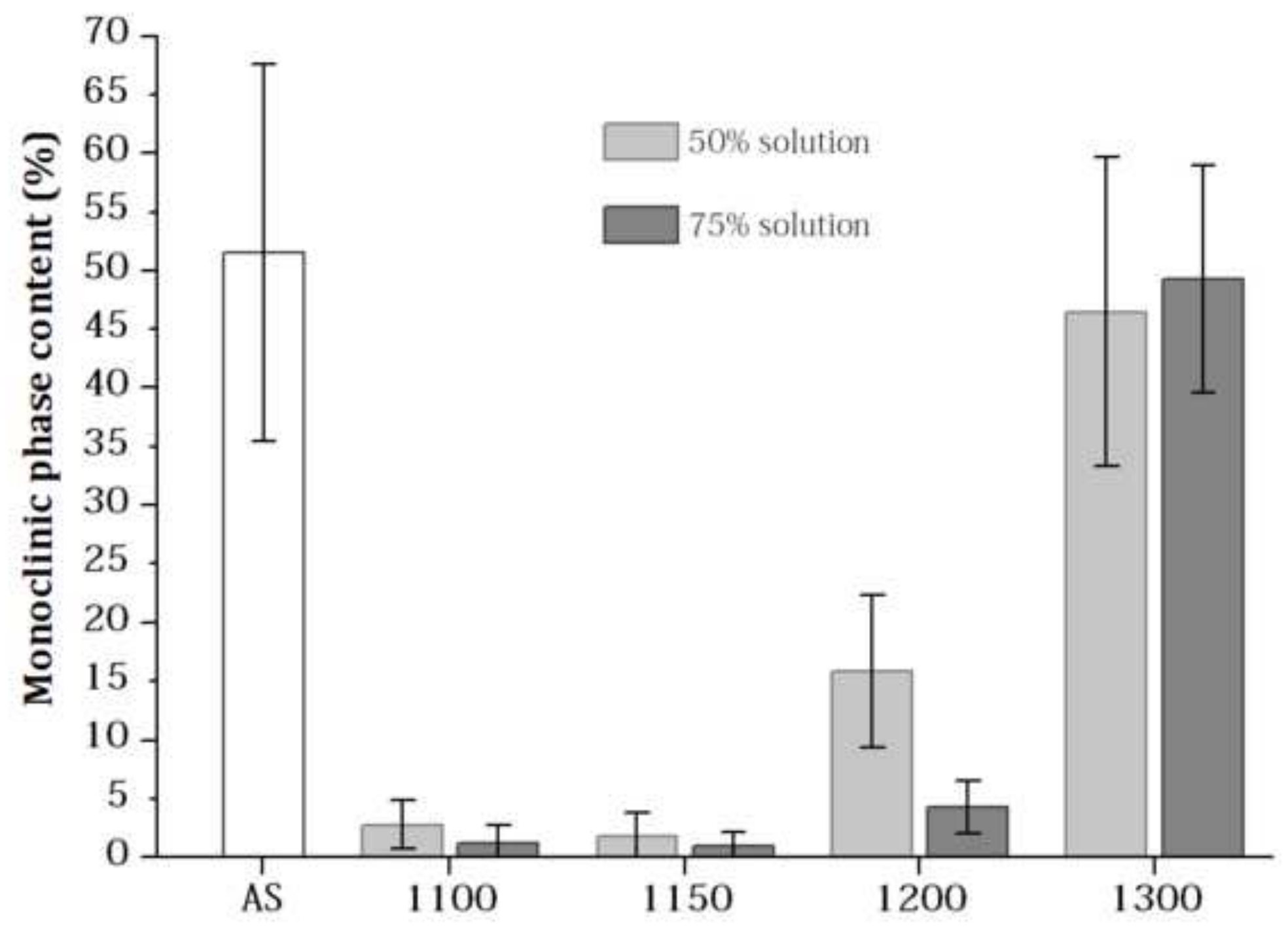



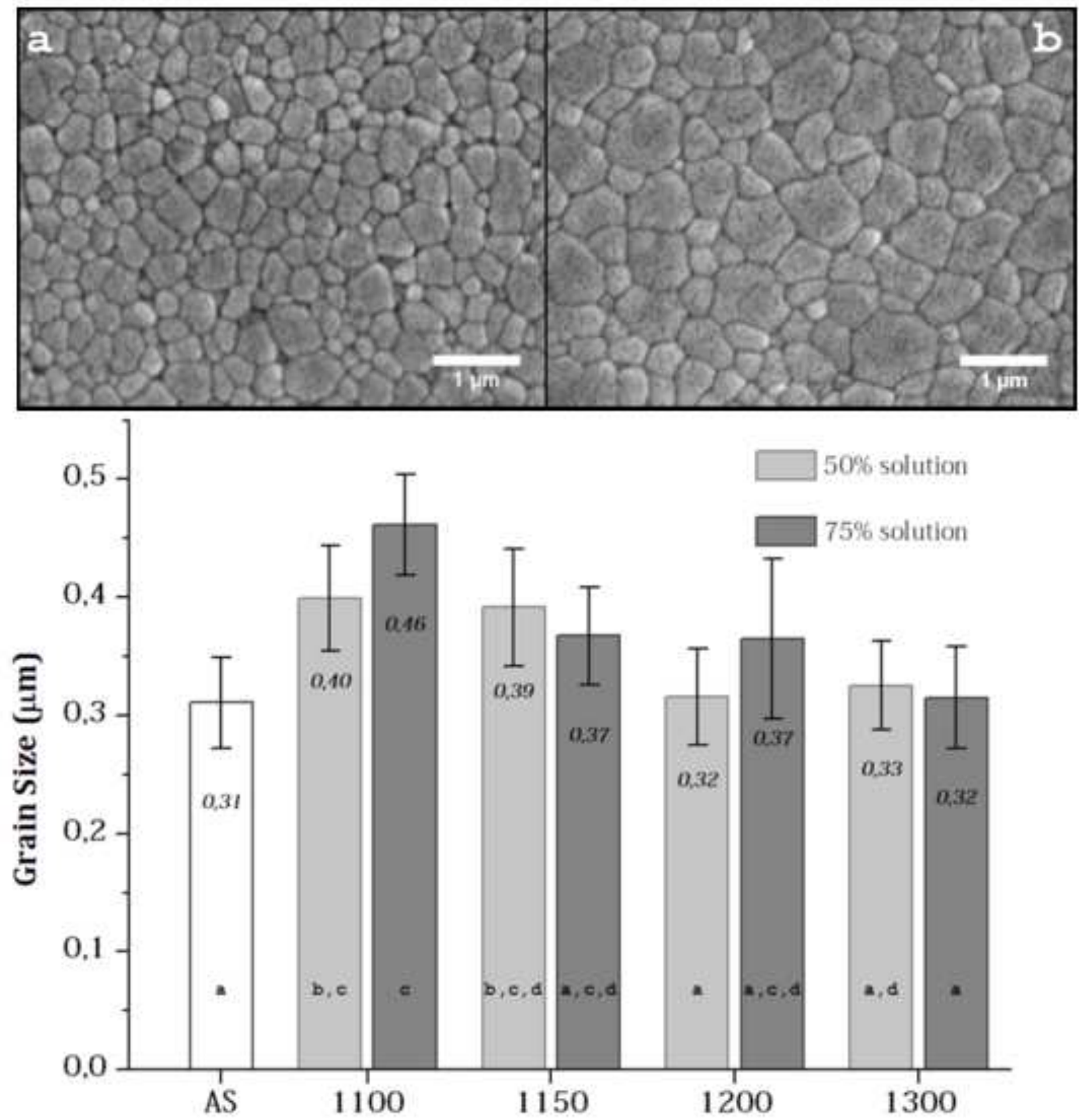
Click here to download high resolution image
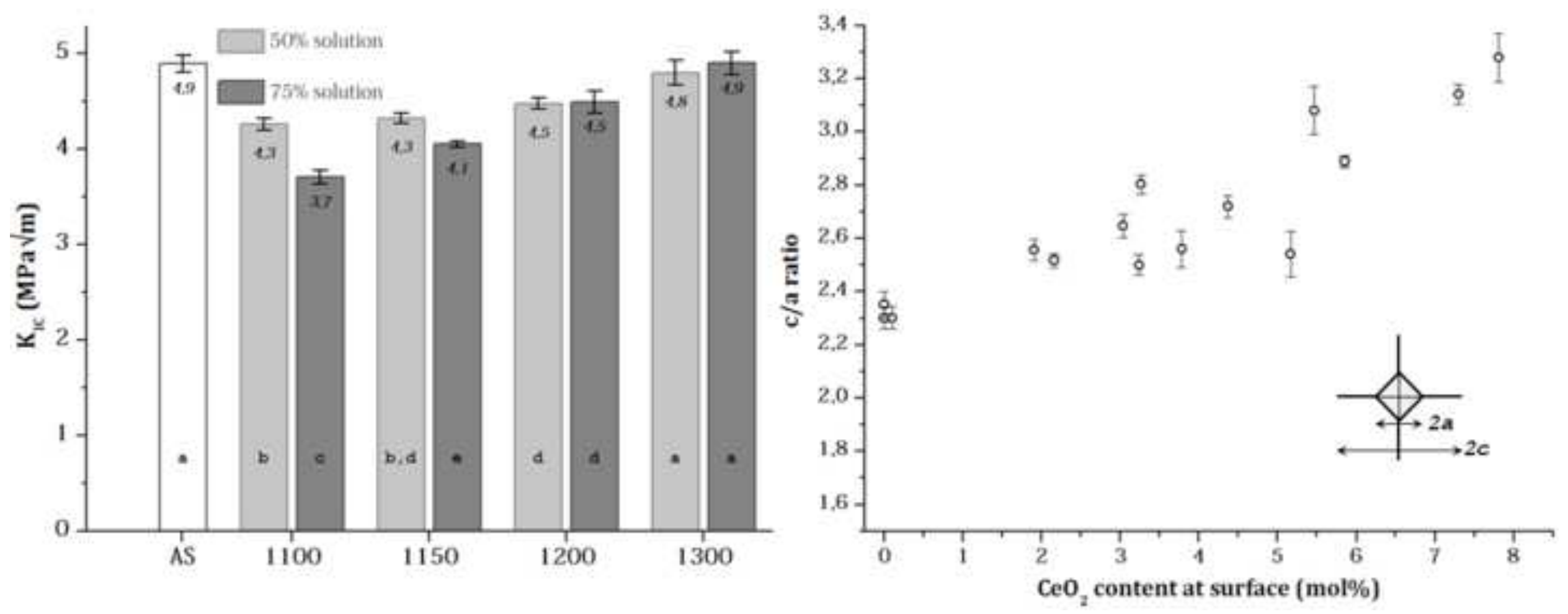


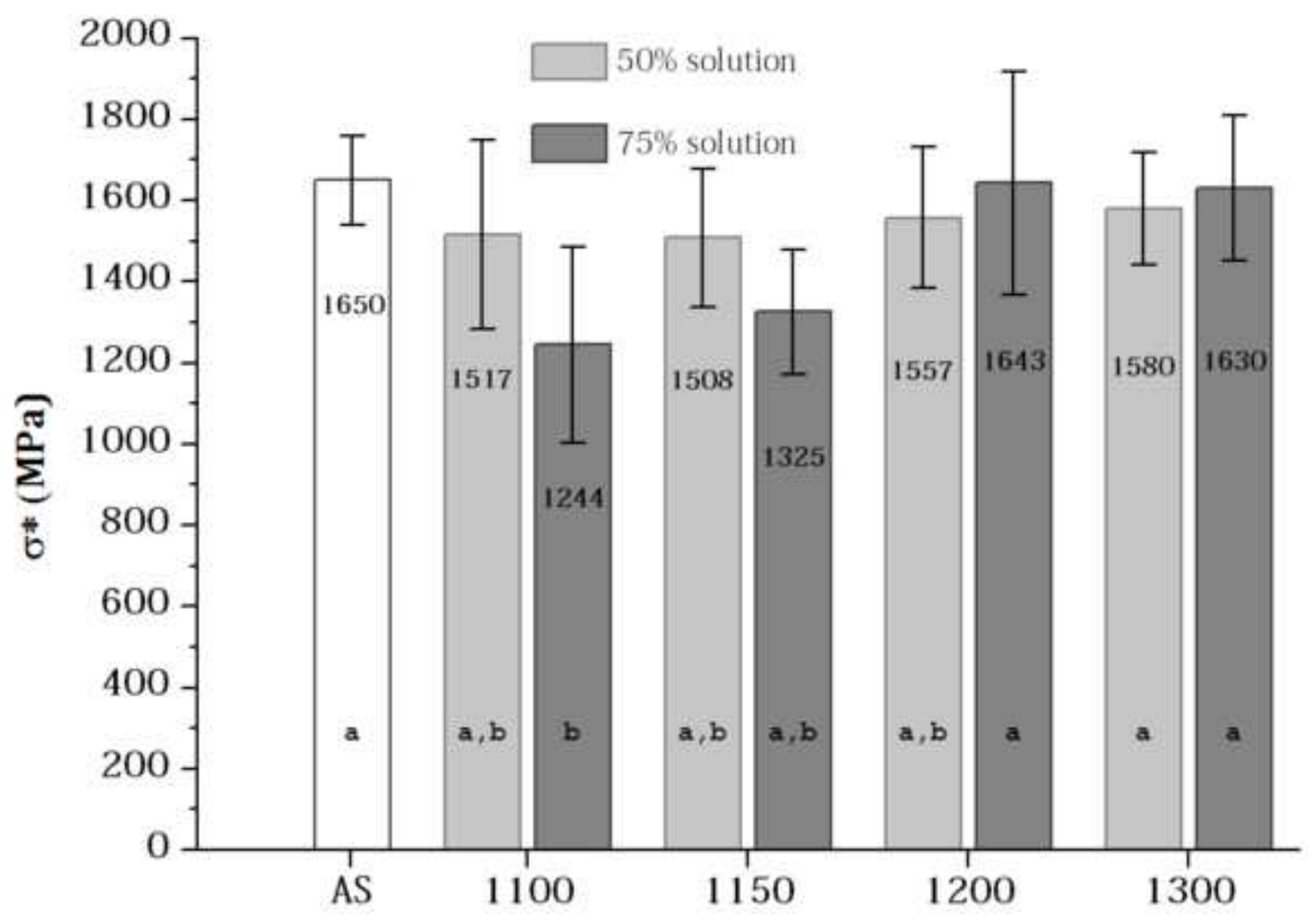


Click here to download high resolution image
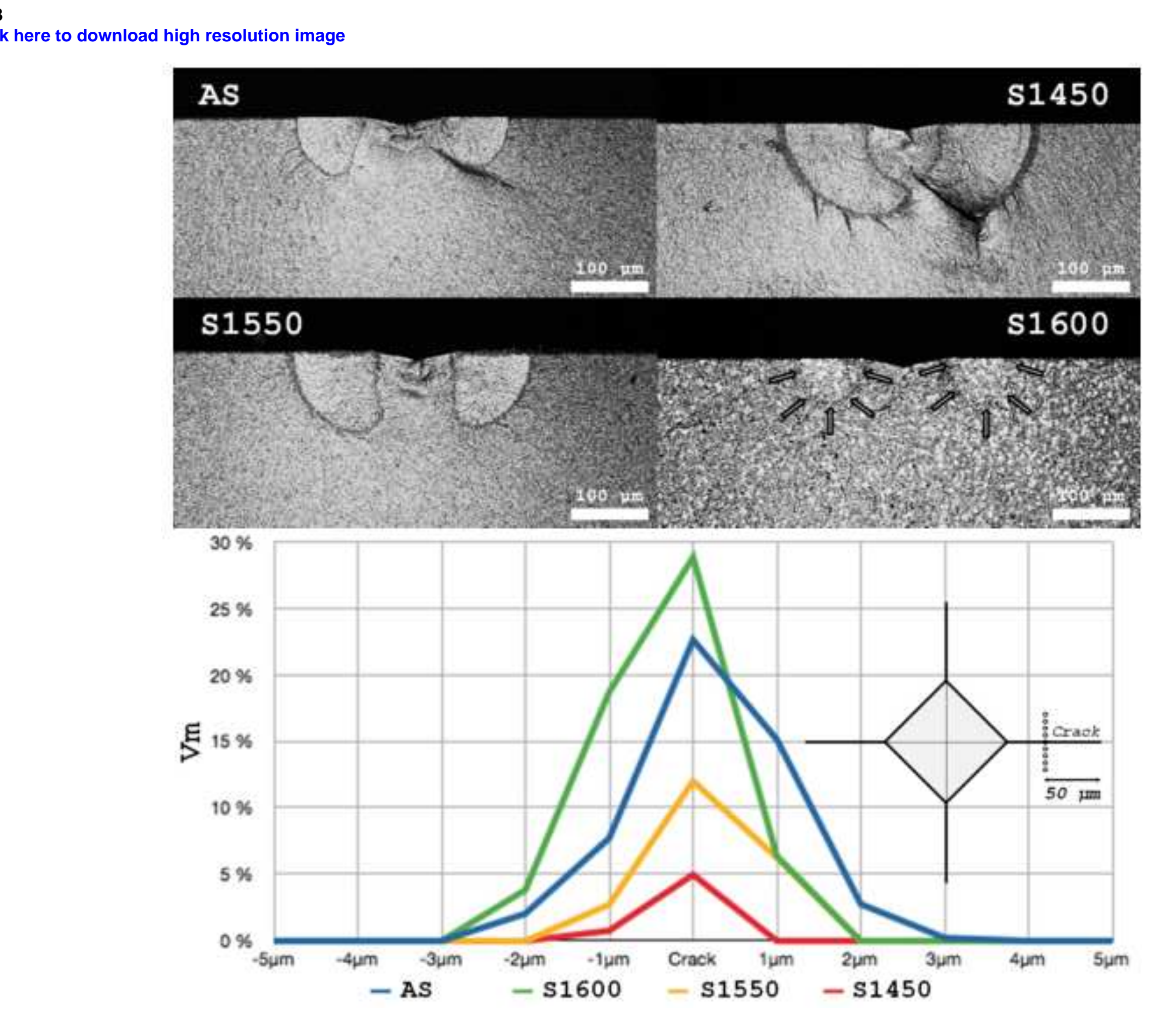

.

.
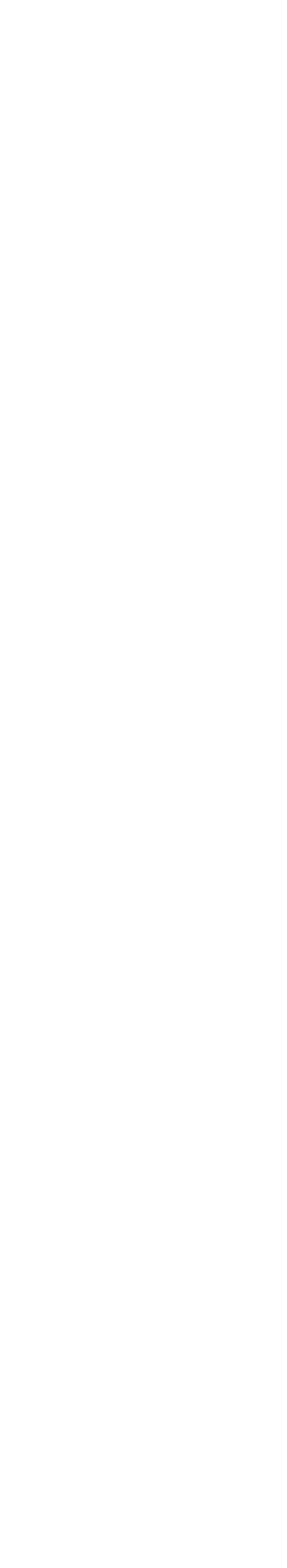
Supplementary Material

Click here to download Supplementary Material: Supporting_Info_Reviewed.docx

\begin{abstract}
Click here to download Supplementary Material: Supporting Info_Reviewed.docx
\end{abstract}

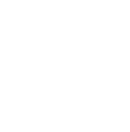

(1)

$\sqrt{10}$

(1) (1)

(1)

(1)

(1)

(1)

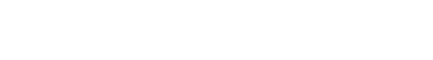

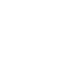

